\title{
Animal Spirits and Risk in Financial Markets
}

\author{
Jukka Ilomäki ${ }^{1}$ \\ University of Tampere \\ jukka.ilomaki@uta.fi
}

Received: 28 April 2017 / Revised: 12 February 2018 / Accepted: 13 February 2018 / Published online: 19 February 2018

\begin{abstract}
Keynes argues that a beauty contest in financial markets is a combination of rational higher-order beliefs and market psychology or animal spirits. We find that a stable equilibrium, where also market psychology is included, can be possible if uninformed investors agree to reduce their required rate of return indicating that they enlarge the risk of their investment with the animal spirits component.
\end{abstract}

JEL Classification: G11, G12

Keywords: Risk, Portfolio Choice, Asset Pricing

\section{INTRODUCTION}

Keynes (1936) writes: "professional investment may be likened to those newspaper competitions in which competitors have to pick out the six prettiest faces from a hundreds of photographs, the prize being awarded to the competitor whose choice most nearly corresponds to the average preferences of the competitors as a whole". Keynes argues that investors' decisions in financial markets are affected by higher-order beliefs and he calls this phenomenon "beauty contest in the financial markets". He argues that the beauty contest can be divided into two effects: rational higher-order beliefs and market psychology. Shiller (2014) calls the latter component "animal spirits", and he follows Keynes (1921) in defining animal spirits as a "gut feeling that rises from the ambiguity of directly unobservable probabilities of future returns."

DeLong et al. (1990), Froot et al. (1992), and Campbell and Kyle (1993), among others, analyze the effect of animal spirits on the equilibrium price of a risky asset. Their basic assumption is that technical traders coordinate their actions, which results in a stable equilibrium. Furthermore, Allen et al. (2006), Bacchetta and VanWincoop (2008) analyze only the effect of rational higherorder beliefs resulting in returns predictability in equilibrium. Ilomäki (2016a; 2016b; 2017) connects rational higher order expectations and animal spirits in the same framework, and shows that the animal spirits component reduces expected returns for investors when the beauty contest is present. However, the returns depend on crucially on the level of the risk-free rate return. In these studies, one half of the rational investors are assumed as informed and the other half

Faculty of Management, FI-33014 University of Tampere, Finland. Phone number: +358401366117. 
uninformed. In this article, the proportion of informed investors is $0<\mu<1$ and the focus is on the risk of uninformed investors, both with and without the animal spirits component.

Samuelson (1973) argues that in efficient markets with risk-neutral investors, the following must hold:

$$
P_{t}=V_{t}=E_{t} \sum_{s=1}^{\infty} \frac{D_{t+s}}{\left(1+r^{f}\right)^{s}}
$$

where $P_{t}$ is the equilibrium price, $V_{t}$ is the fundamental value, $D_{t}$ is dividend, $E_{t}$ is the expectations operator, and $r^{f}$ is the constant risk-free rate of return. In Samuelson's definition investors are assumed to be risk-neutral. In real life, however, a rational investor cares also about the risk of investment besides the reward. The risk in financial markets can be defined as the variation of returns, which leads to the well-known mean-variance paradigm (Markowitz 1952; Sharpe 1964). Thus, a risk premium $\omega$ should be added. Shiller (2014) argues that stock markets seem to follow

$$
P_{t}=E_{t} \sum_{s=1}^{\infty} \frac{D_{t+s}+\omega A_{t+s-1}}{\left(1+r^{f}+\omega\right)^{s}}
$$

where $\omega$ denotes the risk premium, and $A_{t}$ denotes the animal spirits component. Note that the rational higher order expectations is absent in this model.

In this paper, the animal spirits component is specified by assuming coordinated actions of a large group of uninformed investors, and short-lived and risk-averse rational investors. The latter assumption is based on performance-based arbitrage, where the success in investing is monitored by short period intervals (Shleifer and Vishny 1997).

Our basic finding is that the animal spirits component is present in a stable Keynesian beauty contest equilibrium only if the short-lived uninformed investors accept more risk compared to the case, where when only rational higher-order beliefs are present.

Section 1 presents the model. Section 2 describes the equilibrium with only rational higherorder beliefs. Section 3 presents the equilibrium, when also market psychology is included. Section 4 concludes.

\section{THE MODEL}

The model follows Ilomäki (2016a; 2016b). The economy consists of rational risk-averse (CARA, with equal tolerance of risk $v$ ) investors who live for two periods, investing in period one, and consuming in period two. There is an infinitely lived risky asset (share of firm F) and a constant risk-free rate of return $r^{f}$. The atomistic rational investors have asymmetric information so that $0<\mu<1$ is the share of informed investors and $1-\mu$ is the share of uninformed investors in every period. That is, there are four kinds of rational investors in every trading period: young informed and uninformed investors who open their positions (demand at time $t$ ) and old informed and uninformed investors who close their positions (supply at time $t$ ) Within the interval $[0,1]$, there is a continuum of young and old investors in every period. The investors are constrained by wealth so that the young investors $y$ at time $t$ have the same initial wealth $w_{t}^{y}$. Short selling is available to young investors, and there are no transaction costs or taxes.

In the economy, the natural logarithm of the dividend $D_{t}$ follows a random walk

$$
\ln D_{t}=\ln D_{t-1}+e_{t}^{d}
$$


where $e_{t}^{d} \sim W N\left(0, \sigma_{d}^{2}\right)$. We assume that firm $\mathrm{F}$ pays $D_{t}$ to the investors at time $t$ after trading, and that the dividend information is private. The informational advantage of the young informed investor derives from observing private information about $D_{t}, D_{t+1}, D_{t+2}$ and $\mu$. The history of equilibrium prices $\left(P_{t-1}, P_{t-2}, P_{t-3}, \ldots\right)$ and the risk-free rate $r^{f}$ comprise information common to all investors. In addition, we assume noisy net supply of the stock by dumb traders $\left(D U_{t}\right)$ distributed $e_{t}^{d u} \sim N\left(0, \sigma_{d u}^{2}\right)$. We assume that the dumb traders always lose money in their trading, implying that they act as liquidity providers. The market clears, when

$$
\int_{y} x_{y}-\int_{o} s_{o}+e_{t}^{d u}=0
$$

where $x$ is the demand for stock of young investors $(y)$ and $s$ is the supply of the stock by old investors $(o)$. The equilibrium condition assures that demand per share is one in the equilibrium. Furthermore, we assume that the excess returns on the risky asset follow normal distribution. This assumption assures that the conditional variance of the excess returns is constant.

\section{EQUILIBRIUM PRICE WITH RATIONAL HIGHER-ORDER BELIEFS}

A risk-averse young investor, who lives for two periods, maximizes his/her utility by allocating wealth between risky and risk-free assets. The net excess return on a risky share is

$$
R_{t+1} \equiv \frac{P_{t+1}-P_{t}+D_{t+1}}{P_{t}}-r^{f}
$$

The young investor solves the maximization problem.

$$
\operatorname{Max}\left[E\left(-e^{-v c_{t+1}} \mid \theta_{t}^{y}, w_{t}^{y}\right)\right]
$$

where $\theta_{t}^{y}$ is the information set, $v$ is the common coefficient of risk aversion, $c$ is consumption, and $w_{t}^{y}$ is the investor's initial wealth. The budget constraints read

$$
\begin{gathered}
c_{t+1}=x^{f}\left(1+r^{f}\right)+x^{r} E_{t}\left(R_{t+1}\right), \\
w_{t}^{y}=x^{f}+x^{r},
\end{gathered}
$$

where $x$ is the amount of money. Assume normally distributed extra consumption, (because of normally distributed excess returns), take expectations in Equation (2), and plug the consumption constraint into the utility function to get

$$
E_{t}\left(U\left(c_{t+1}\right)\right)=-e^{-v x^{r} E_{t}\left(R_{t+1}\right)+\frac{v^{2}}{2} x^{r^{2}} \sigma_{r}^{2}}
$$

where $\sigma_{r}^{2}$ is the variance of excess returns. Since the informed investors have better information about risky assets, it must be that $\sigma_{r i}^{2}<\sigma_{r u}^{2}$. Moreover, since the investors observe $r^{f}$, its variance is zero. Maximize (Equation 3) with respect to $x^{r}$, use Equation (2) and note that the demand per risky asset's share is one in the equilibrium. Thus, the first order condition for the risky asset reads 


$$
\frac{E_{t}\left[\frac{P_{t+1}-P_{t}+D_{t+1}}{P_{t}}\right]-r^{f}}{v \sigma_{r}^{2}}=1 \quad \Rightarrow \frac{E_{t}\left[P_{t+1}+D_{t+1}\right]}{\left(1+r^{f}+v \sigma_{r}^{2}\right)}=P_{t} .
$$

In Equation (4),

$$
E_{t}\left[\frac{P_{t+1}-P_{t}+D_{t+1}}{P_{t}}\right]-r^{f}=v \sigma_{r}^{2}=\omega
$$

defines the risk premium. Since $\sigma_{r}^{2}$ varies between informed and uninformed investors, the risk premiums must also vary between them because of equal coefficients of risk aversion $v^{i}=v^{u}=v$. Thus, in the equilibrium, we obtain

$$
\frac{\omega_{i}}{\sigma_{r i}^{2}}=\frac{\omega_{u}}{\sigma_{r u}^{2}} \Rightarrow \frac{\omega_{i}}{\omega_{u}}=\frac{\sigma_{r i}^{2}}{\sigma_{r u}^{2}}
$$

where the subscripts $i$ and $u$ refer to informed and uninformed investors, respectively. Solve Equation (4) forward by substituting out future prices. Then, as the horizon approaches infinity, Equation (4) produces

$$
P_{t}=E_{t} \sum_{s=1}^{\infty} \frac{D_{t+s}}{\left(1+r^{f}+\omega\right)^{s}} .
$$

According to the properties of random walk, the change in the dividend at time $t$ is permanent. Thus, Equation (7) results in the simple perpetuity model

$$
V_{t}=\frac{D_{t+1}}{r^{f}+\omega_{i}}
$$

where $V_{t}$ is the fundamental value per share of stock $\mathrm{F}$, and $r^{f}+\omega_{i}=r_{i}^{n}$ is the net required rate of return for an informed investor.

Recall that the young (old) informed investors have private information about $D_{t}, D_{t+1}, D_{t+2}$ $\left(D_{t-1}, D_{t}, D_{t+1}\right)$. Therefore, a young (old) informed investor solves the fundamental values $V_{t-1}, V_{t}, V_{t+1}\left(V_{t-2}, V_{t-1}, V_{t}\right)$. The rational pricing rule for young and old investors is simply

$$
P_{t}=V_{t}
$$

because these atomistic investors have the same information and old (young) recognizes that young (old) observes this. Notice that a young informed investor chooses his/her buy or sell position according to $V_{t+1}$. However, the uninformed investors observe only past equilibrium prices and the constant risk-free rate $r^{f}$, resulting in the equal risk premium $\omega_{u}$ and the required rate of return $1+r^{f}+\omega_{u}=1+r^{f}+v \sigma_{r u}^{2}=1+r_{u}^{n}$. Thus, the pricing rule is

$$
P_{t}=\left(1+r_{u}^{n}\right) P_{t-1}
$$

Note that the uninformed investors do not observe dividends. 
Given that $\mu$ is the share of the rational young and old informed investors and $1-\mu$ is the share of the uninformed investors, the rational choice equilibrium price in this economy is

$$
P_{t}=\mu V_{t}+(1-\mu)\left(1+r_{u}^{n}\right) P_{t-1}
$$

with the restriction of Equation (6). Thus, the larger is the proportion of informed investors among rational investors, the closer is the equilibrium price to the fundamental value.

As far as $1>\mu>0$, Equation (9) implies that $P_{t} \neq V_{t}$ in every step suggesting that $P_{t}=V_{t}+C_{t}$ where $C_{t}$ describes all errors when $P_{t} \neq V_{t}$ (Shiller 2014). In this economy, $C_{t}$ denotes the predictability in returns component implying that

$$
P_{t}=\mu\left(V_{t}+C_{t}^{i}\right)+(1-\mu)\left[\left(1+r_{u}^{n}\right) P_{t-1}+C_{t}^{u}\right]
$$

Solving $C_{t}^{u}$ from Equation (10), we obtain

$$
C_{t}^{u}=\frac{\mu}{1-\mu} P_{t}-\frac{\mu}{1-\mu} V_{t}-\frac{\mu}{1-\mu} C_{t}^{i}+\Delta P_{t}-r_{u}^{n} P_{t-1}
$$

The uninformed investors observe only $r_{u}^{n} P_{t-1}$ on the right-hand side directly. However, assuming stationary returns, an uninformed investor infers $\mathrm{E}\left(\Delta P_{t}\right)=\Delta P_{t-1}$, and reducing the approximation of unobservable dividend $r_{u}^{n} P_{t-2}$, we obtain

$$
C_{t}^{u}=\Delta P_{t-1}-r_{u}^{n} P_{t-2}
$$

For a young informed investor, Equation (11) reads $C_{t}^{i}=P_{t}-V_{t}+\frac{1-\mu}{\mu}\left(-C_{t}^{u}+\Delta P_{t}-r_{u}^{n} P_{t-1}\right)$ where $C_{t}^{u}=\Delta P_{t}-r_{u}^{n} P_{t-1}$. Then, using the cointegration results of Engle and Granger (1987), the difference $P_{t-1}-V_{t-1}$ gives the optimal forecast for $C_{t}$. Thus, we obtain

$$
C_{t}^{i}=P_{t-1}-V_{t-1}
$$

Following Equations (9), (11) and (12), the equilibrium price series follows

$$
P_{t}=\mu\left(V_{t}+P_{t-1}-V_{t-1}\right)+(1-\mu)\left[\left(1+r_{u}^{n}\right) P_{t-1}+\Delta P_{t-1}-r_{u}^{n} P_{t-2}\right]
$$

with the restriction of Equation (2). To prove that Equations (9) and (13) produce the identical equilibrium price $P_{t}$ manipulate Equation (12), to obtain

$$
\Delta P_{t}=\mu \Delta V_{t}+(1-\mu)\left(\Delta P_{t-1}+r_{u}^{n} \Delta P_{t-1}\right)
$$

Taking the difference of sequential variables from Equation (9) yields Equation (14). Thus, Equation (14) proves returns predictability (because it includes $\Delta P_{t-1}$ ) in the equilibrium. This is consistent with Allen et al. (2006), Bacchetta and VanWincoop (2008) with rational higher-order beliefs. 


\section{EQUILIBRIUM PRICE WITH ANIMAL SPIRITS}

Following Ilomäki (2016a; 2016b), suppose that the uninformed investor starts to include an animal spirits component $A_{t}$ in the pricing equation $\left(1+r_{u}^{n}+A_{t}\right) P_{t-1}$ suggesting that $C_{t}^{u}=A_{t} P_{t-1}$. Following DeLong et al. (1990), among others, we assume that the uninformed investors can coordinate their actions perfectly.

Additional Assumption 1: Uninformed investors coordinate perfectly in their animal spirits component to obtain an identical product of $A_{t}$, which is the product of overreacted demand for stock per share.

Note that the overreaction can be positive or negative. In addition, we follow Santos and Woodford (1997) by assuming that infinite bubbles are impossible in the economy. This is to say that $P_{t}$ and $V_{t}$ cannot drift apart forever.

Additional Assumption 2: Infinite bubbles are impossible in the economy.

An informed investor observes that Equation (9) does not hold at time $t-1$. Then, being rational (since $P_{t}$ and $V_{t}$ cannot drift apart forever), an informed investor $i$ uses the cointegration results of Engle and Granger (1987) giving the optimal forecast for the product of $A_{t}$. Thus, we obtain

$$
A_{t}^{i} P_{t-1}=P_{t-1}-V_{t-1}
$$

Then, the equilibrium price series follows

$$
P_{t}=\mu\left(V_{t}+P_{t-1}-V_{t-1}\right)+(1-\mu)\left[\left(1+r_{u}^{n}+A_{t}\right) P_{t-1}\right]
$$

To find stable equilibrium conditions (Equation 15), it is useful to analyze it in $\Delta P_{t} / P_{t-1}$ series. By manipulation of Equation (15), we have it as

$$
\frac{\Delta P_{t}}{P_{t-1}}=\mu \frac{\Delta V_{t}}{P_{t-1}}+(1-\mu)\left(r_{u}^{n}+A_{t}\right) .
$$

This shows that the actual $\Delta P_{t} / P_{t-1}$ is the sum of two weighted components, $\Delta V_{t} / P_{t-1}$ and $r_{u}^{n}+A_{t}$. Because an informed investor $i$ observes $V_{t}$ and $V_{t-1}$, then he/she recognizes that $\Delta V_{t} / P_{t-1}=r_{i}^{n}+e_{t}^{v}$, where $e_{t}^{v} \sim N\left(0, \sigma_{v}^{2}\right)$. For an uninformed investor $u E\left(\Delta P_{t} / P_{t-1}\right)=r_{u}^{n}+A_{t}$. Thus,

$$
E\left(\frac{\Delta P_{t}}{P_{t-1}}\right)=\mu r_{i}^{n}+(1-\mu)\left(r_{u}^{n}+A_{t}\right)
$$

However, according to the assumption that infinite bubbles are impossible in the economy, there has to be a long-run equilibrium (because $\Delta V_{t} / P_{t-1}=r_{i}^{n}+e_{t}^{v}$ ), in which

$$
r_{i}^{n}=\mu r_{i}^{n}+(1-\mu)\left(r_{u}^{n}+A_{t}\right) \Rightarrow r_{i}^{n}-r_{u}^{n}=A_{t}
$$


Equation (16) produces that $\omega_{i}-\omega_{u}=A_{t}$. The additional assumption (2) and Equation (6) indicate that $\omega_{i}-\omega_{u}=A_{t}<0$. To see this, we plug $\omega_{u}=\omega_{i}-A_{t}$ into Equation (6), obtaining

$$
A_{t}=-\frac{\omega_{i}\left(\sigma_{u}^{2}-\sigma_{i}^{2}\right)}{\sigma_{i}^{2}} .
$$

Thus, Equation (17) shows that the effect of animal spirits can only be positive if $\sigma_{u}^{2}<\sigma_{i}^{2}$. Recall that $\sigma^{2}$ is the variation of excess returns. Additional assumption (2) assures that the informational advantage of informed ones produces $\sigma_{u}^{2}>\sigma_{i}^{2}$ among subsequent generations resulting $\sigma_{u}^{2}>\sigma_{i}^{2}$ in stable equilibrium. This implies the negative effect of $A_{t}$.

Corollary 1: Compared to the case where only rational higher-order beliefs is present, a stable equilibrium is possible if only if uninformed investors as subsequent generations agree to reduce their required rate of return indicating that the animal spirits component creates more risk for them.

\section{CONCLUSIONS}

The results indicate that if the uninformed investors add the animal spirits component in their pricing, they add risk in their investment, when the Keynesian higher order expectations already exist in the economy. This happens because infinite bubbles are impossible. This indicates clearly that it is inevitable that a future generation of uninformed investors has to suffer severe losses when the correction eventually happens.

In other words, we find that the animal spirits can be present in the equilibrium only if the uninformed investors reduce required rate of return. This suggests that rational uninformed investors ignore animal spirits in their trading when the Keynesian beauty contest is present, because the animal spirits component increases the risk of investment.

\section{Acknowledgements}

I would like to thank Hannu Laurila, the editor and two anonymous referees.

\section{References}

Allen, F., Morris, S. and Shin, H. (2006) Beauty contests and iterated expectations in asset markets, Review of Financial Studies 19, 719-752.

Bacchetta, P. and Van Wincoop, E. (2008) Higher order expectations in asset pricing, Journal of Money, Credit and Banking 40, 837-866.

Campbell, J. and Kyle, A. (1993) Smart money, noise trading and stock price behavior, Review of Economic Studies 60, 1-34.

DeLong, B., Shleifer, A., Summers, L. and Waldmann, R. (1990) Positive feedback investment strategies and destabilizing rational speculation, Journal of Finance 45, 379-395.

Engle, R. and Granger, C. (1987) Co-integration and error correction: Representation, estimation, and testing, Econometrica 55, 251-275.

Froot, K., Scharfstein D., Stein, J. (1992) Herd on the street: Informational inefficiencies in a market with short-term speculation, Journal of Finance 47, 1461-1484.

Ilomäki, J. (2016a) Animal spirits, beauty contests and expected returns, Journal of Economics and Finance, DOI: $10.1007 / \mathrm{s} 12197-016-9364-8$. 
Ilomäki, J. (2016b) Risk-free rates and animal spirits in financial markets, Annals of Financial Economics 11, No 3, 1-18.

Ilomäki, J. (2017) Connecting theory and empirics for animal spirits, returns and interest rates: A clarification of "risk-free rates and animal spirits in financial markets", Annals of Financial Economics 12, No 1, 1-2.

Keynes, J. (1921) A Treatise of Probability, McMillan, London.

Keynes, J. (1936) General Theory of Employment, Interest and Money, McMillan, London.

Markowitz, H. (1952) Portfolio selection, Journal of Finance 7, 77-91.

Samuelson, P. (1973) Proof that properly discounted present values of assets vibrate randomly, Bell Journal of Economics and Management 4, 369-374.

Sharpe, W. (1964) Capital asset prices: A theory of market equilibrium under conditions of risk, Journal of Finance 19, 425-442.

Shiller, R. (2014) Speculative asset prices, American Economic Review 104, 1486-1517.

Shleifer, A. and Vishny, R. (1997) The limits of arbitrage, Journal of Finance 52, 35-55. 